\title{
A EXTENSÃO UNIVERSITÁRIA COMO POSSIBILIDADE DE FORMAÇÃO DOCENTE PARA ALÉM DA SALA DE AULA
}

University extension as a possibility of teaching training beyond the classroom

La extensión universitária como posibilidad de formación del professor más allá del aula

Alan Navarro Fernandes*

Lucas Salgueiro Lopes**

Arthur Vianna Ferreira***

https://doi.org/10.38117/2675-181X.formov2021.v3i1n5.384-402.

\section{Resumo}

O presente artigo tem como objetivo apresentar as potencialidades da extensão universitária na formação docente, assim como demonstrar a possibilidade de uma troca de saberes entre a academia e seu entorno. Para isso, utilizou-se como estudo de caso as ações extensionistas desenvolvidas na FFP/UERJ pelo projeto de extensão TEAR. As principais fundamentações teóricas para essa pesquisa, partem, sobretudo, das proposições de Isabel Baptista (2005) e Xesús Jares (2008). Como inferência principais trazemos que as atividades extensionistas promovem laços de convivência relevantes para a formação docente, valorizam as demandas das comunidades do entorno da Faculdade e aproximam os conhecimentos universitários à futura realidade docente no Leste Fluminense.

Palavras-chave: Extensão universitária; Formação docente; Educação não escolar.

\begin{abstract}
This article presents the potential of university extension for teacher education, as well as demonstrates the possibility of an exchange between the academy and this neighborhood. For this purpose, we have used extension actions developed by the TEAR extension project from FFP / UERJ. The main theoretical foundations for this research are based on the propositions of Isabel Baptista (2005) and Xesús Jares (2008). As an inference, it's
\end{abstract}


A Extensão Universitária como possibilidade de formação docente para além da sala de aula

understood that extension activities promotes bonds of coexistence relevant to teacher training, values the demands of communities surrounding the Faculty and bring university knowledge closer to the future teaching reality in Eastern of Rio de Janeiro.

Keywords: University Extension; Teacher training; Non-school education.

\section{Resumen}

Este artículo tiene como objetivo presentar el potencial de la extensión universitaria en la formación del profesorado, así como demostrar la posibilidad de un intercambio de conocimientos entre la academia y su entorno. Así, se ha utilizado como caso de estudio las acciones de extensión desarrolladas en FFP / UERJ por el proyecto de extensión TEAR. Los principales fundamentos teóricos de esta investigación se basan en las propuestas de Isabel Baptista (2005) y Xesús Jares (2008). Como inferencia, traemos que las actividades de extensión promueven lazos de convivencia relevantes para la formación docente, valoran las demandas de las comunidades cercanas a la Facultad y acercan el conocimiento universitario a la futura realidad docente del oriente del Rio de Janeiro.

Palabras clave: Extensión Universitaria; Formación de profesores; Educación no escolar.

\section{Introdução}

A extensão, juntamente ao ensino e a pesquisa, compõem um "tripé universitário", ao qual, sem esses elementos, não há universidade, ou, ao menos, não uma universidade em sua potencialidade plena (cf. SANTOS, 2004; SANTOS, 2014). Dessa forma, não há extensão sem pesquisa, assim como não há extensão sem ensino e não deve haver ensino e pesquisa sem extensão. Essas considerações são apontadas tanto no campo teórico, quanto no âmbito legal, uma vez que a composição dessa "trindade" é proposta na legislação brasileira em documentos como a Lei de Diretrizes e Bases (BRASIL, 1996) e a Resolução Curricular Nacional de 2015 (CONSELHO NACIONAL DE EDUCAÇÃO, 2015). Assim, tal como exposto por Ferreira:

As práticas extensionistas estão presentes nos espaços universitários e se constituem em práticas didáticas, não somente relevantes, mas também obrigatórias na formação docente do país. Os artigos $44^{\circ}$ e $53^{\circ}$ da LDB, de 1996 colocam bem essa realidade. A educação superior deverá conter nos seus currículos e programas a extensão com a finalidade de atender os alunos naquilo que é específico do seu próprio programa educativo (FERREIRA, 2019, p. 35). 
Sabendo disso, podemos assentir que, para além dessa perspectiva mais elementar, a extensão pode vir a ser assimilada como um importante fundamento para a formação docente. Haja visto suas potencialidades em colocar o educador em formação em contato com diversas realidades sociais, as ações extensionistas acabam por possibilitar valiosas experiências práticas em ambientes educacionais não escolares. Tais experiências terminam sendo vistas como ainda mais importantes ao considerar as "novas" demandas (em especial, a partir da passagem para o século XXI) direcionadas às práticas docentes, agora tão cobradas por uma "construção do futuro" (cf. NÓVOA, 1999).

Essa construção do futuro, todavia, coloca como desejável uma formação que capacite o docente a ser, em simultâneo, "global" e "local" (cf. CHARLOT, 2008; PORFÍRIO, 2012; ZAINKO, 2010), o que requer, no entanto, "uma cultura profissional que não é a cultura tradicional do universo docente" o que faz com que "o professor, que não foi e ainda não é formado para tanto, fique um pouco perdido." (CHARLOT, 2008, p. 20). Assim, visto a dificuldade em gerar um ensino contextualizado com o entorno da instituição educacional, considerando que "em um país urbanizado como é o Brasil, cada vez menos a professora compartilha o espaço de vida dos seus alunos, em especial o dos seus alunos pobres" (CHARLOT, 2008, p. 31), a extensão viabiliza um contato do docente-educando com uma realidade que, muito possivelmente, lhe será (ou já é) cobrado ter o "know-how" necessário para atuar.

Da mesma forma, podemos situar a extensão universitária como relevante meio de diálogo entre a academia, seus sujeitos e seu entorno, visto essa ser, por natureza, dentre outras práticas, uma ação subversiva (cf. GABRIEL, 2008) para com as estruturas sociais por vezes estáticas na sociedade brasileira. Sousa (2010, p. 120) irá ponderar que esse aspecto está inerente a sua concepção:

A extensão universitária surge como instrumento a ser utilizado pela universidade para a efetivação do seu compromisso social e também como articuladora de suas relações. Ela vai receber e efetivar este compromisso, principalmente com as camadas carentes. (SOUSA, 2010, p. 120)

Tal compromisso social é magnânimo e capaz de proporcionar o acesso dos estudantes de origem popular (cf. GABRIEL; MOEHLECKE, 2011) às instituições de ensino superior, assim como, podem contribuir para o seu letramento, acesso à novos saberes e outras mais dependendo do contexto ao qual a universidade está inserida. De certa forma, a extensão acaba por tentar apaziguar as desigualdades sociais existentes em nossa sociedade, oferecendo às populações algo que é delas por direito: o acesso à uma educação pública de qualidade. Como destaca Santos (2014): 
A Extensão Universitária como possibilidade de formação docente para além da sala de aula

Por meio da extensão, a universidade tem a oportunidade de levar até a comunidade os conhecimentos de que é detentora, os quais são produzidos com a pesquisa e que normalmente divulgam o ensino. É uma forma de a universidade socializar e democratizar o saber científico, de modo a este não se traduzir em privilégio apenas da minoria da população (universitária), mas difundido também à comunidade não acadêmica, consoante os próprios interesses dessa mesma comunidade. (SANTOS, 2014, p. 14).

Dessa maneira, neste artigo pretende-se articular algumas reflexões teóricas e práticas referentes à extensão universitária, tal como, sua historicidade e os meios que perpassam a execução de suas ações. Por meio disso, têm-se como objetivos apresentar as práticas extensionistas como elementos importantes na formação docente (inicial e continuada) e demonstrar como essas podem vir a ser um componente para a disseminação do saber universitário para as diversas camadas sociais, em especial, as camadas empobrecidas.

Para ilustrar isso, utilizaremos como estudo de caso as ações extensionistas desenvolvidas na Faculdade de Formação de Professor da UERJ, localizada em São Gonçalo, município da região metropolitana do Rio de Janeiro, a partir das pesquisas em desenvolvimento pelo projeto de extensão TEAR (Troca de Experiências em Ações extensionistas na Região de São Gonçalo e Adjacentes) ${ }^{1}$. As principais fundamentações teóricas para essa pesquisa, partem, sobretudo, de autores como Isabel Baptista (2005) e Xesús Jares (2008). A ação extensionista supracitada é concebida a partir de um longo processo histórico de estruturação de práticas extensionistas ao qual se faz elementar para compreender essas experiências em seu contexto específico.

\section{As origens da extensão universitária no Brasil e a sua função social.}

No Brasil, a extensão teve o seu ponto de partida no início do século XX. As primeiras experiências com as ações extensionistas no país foram baseadas no modelo francês de "universidades populares" (um modelo mais associado às demandas populares e a classe operária) e no modelo americano chamado de "university extension" (mais voltado aos interesses das classes mais abastadas). Segundo Ana Dubeux (2018, p. 5),

\footnotetext{
1 O TEAR é um projeto de extensão registrado no Pró-reitoria de Extensão (PR3-DEPEXT) da Universidade do Estado do Rio de Janeiro desde 2018. Ele tem como objetivos estudar a articulação dos diversos projetos de extensão do Departamento de Educação da Faculdade de Formação de Professores da Universidade do Rio de Janeiro (FFP/UERJ) e a comunidade do Leste Fluminense.
} 
ainda hoje, persiste essa dicotomia entre os dois modelos no contexto brasileiro. Entretanto, no presente, é possível observar de modo mais explícito que as práticas extensionistas possuem uma preocupação maior com o aspecto da transformação social voltado às camadas populares.

Quanto a uma das origens possíveis para as ações de extensão no Brasil, Dubeux, resgatando alguns dos apontamentos vistos em Correia (2002, p. 131), irá ponderar que:

[...] foi no Rio de Janeiro que apareceu a primeira preocupação de "levar a universidade ao povo, mesmo antes que existissem universidade no Brasil". Mas pouco tempo depois, foram criadas as "Universidades Populares", que tinham como objetivo "oferecer instrução superior e educação social ao proletariado, através da difusão do saber e da beleza em todas as suas formas, principalmente pela oferta de cursos e conferências". (DUBEUX, 2018, p. 5)

Foi em 1931, durante o governo de Getúlio Vargas, que houve a promulgação do "Estatuto das Universidades Brasileiras" e a oficialização da extensão reconhecida pelo Estado. Todavia, foi posteriormente, nas décadas de 1980 e 1990, que a extensão ganhou notoriedade e passou a ser mencionada até mesmo na Constituição Federal, possuindo também, no mesmo período, uma política nacional de extensão.

Em 1987 foi criado o Fórum de Pró-Reitores de Extensão das Universidades Públicas Brasileiras (FORPROEXT). A origem dessa iniciativa está relacionada a um movimento de escolha de reitores comprometidos com as causas sociais. Por sua vez, esses reitores foram incumbidos de selecionar pró-reitores de extensão que teriam como uma de suas principais responsabilidades dar estrutura à extensão universitária no Brasil. Para tanto, seria necessário se ater a três itens: o conceito, a institucionalização e o financiamento.

O objetivo do FORPROEX é estabelecer coletivamente políticas e diretrizes que ajudem a institucionalizar as práticas de extensão, fortificando as ações coletivas das instituições regionais e das pró-reitorias de extensão nas universidades públicas. Esse conjunto de medidas dá suporte para dialogar e compreender as diferenças regionais causadas pela relação entre a academia e a sociedade, fazendo com que a universidade se expanda em um "movimento pluralista".

Dessa forma, o FORPROEXT passa então a discutir o conceito de extensão para que as práticas compartilhassem de uma mesma uniformidade no âmbito institucional. Essa articulação foi fundamentada junto a ideia de que a extensão, somada ao ensino e a 
A Extensão Universitária como possibilidade de formação docente para além da sala de aula

pesquisa, iriam compor uma tríade que seria a "pedra angular" de toda a estrutura universitária.

De sua concepção até então, o Fórum de Pró-Reitores reúne-se periodicamente a partir de temáticas centrais, das quais podemos citar: a conceituação e a institucionalização da extensão universitária; a relação universidade e sociedade; os diálogos entre extensão, cultura e cidadania; além de diversas outras temáticas. A partir daí, o Fórum passa a definir a extensão universitária como

[...] o processo educativo que articula ensino e pesquisa de forma indissociável e que torna viável a relação transformadora entre universidade e sociedade (...) A extensão é não apenas a principal ferramenta para este processo dialético entre teoria e a prática, mas é também um trabalho interdisciplinar que favorece uma visão integrada do social no interior da universidade. (FORPROEXT, 1990, p. 14).

Sendo assim, infere-se que as ações extensionistas podem vir a ser uma prática mobilizadora no processo formativo de seus diferentes sujeitos, uma vez que são capazes de proporcionar um diálogo efetivo entre a universidade - enquanto corpo docente, discente e técnico - e a população geral. Além disso, a função social da universidade não se dá somente nas possibilidades que esta, enquanto uma instituição ímpar no processo formativo e todos os agentes que a compõem, pode oferecer à sociedade. A interação entre sociedade e universidade, quando realizada de modo prático e reflexivo, pode vir a proporcionar um encurtamento na discussão de pautas valorosas para esses grupos sociais, outrora afastados. Além disso, essas possíveis pautas abordadas nas atividades extensionistas auxiliam à formação docente na construção do saber-fazer necessário para a sua prática que, como já mencionado anteriormente, busca um ponto de equilíbrio entre a prática "global" e "local".

Outro aspecto importante das ações extensionistas é sua potencialidade em levar para grupos mais abrangentes de nossa sociedade o conhecimento científico gerado a partir das pesquisas em universidades. Como podemos ver, segundo dados da pesquisa "Research in Brazil" (CROSS et al., 2018) encomendada pela CAPES (Coordenação de Aperfeiçoamento de Pessoal de Nível Superior) e produzida pela "Clarivate Analytics" entre os anos de 2011 e 2016, o impacto que a produção científica, particularmente das instituições públicas, representa para o Brasil é crescente. O estudo aponta, a partir de dados como o número de citações em artigos, que a pesquisa brasileira vem ganhando progressivamente uma maior notoriedade e, possivelmente, em 2021 poderá se comparar à média mundial em número de produções citadas em trabalhos. O estudo dispõe ainda $\mathrm{O}$ 
dado de que $95 \%$ das pesquisas científicas brasileiras são realizadas por instituições públicas.

Dessa forma, comprova-se que os pesquisadores dessas instituições, financiados principalmente por dinheiro público, são responsáveis por parte majoritária do conhecimento científico produzido no Brasil. Esses dados revelam a importância dessas instituições e o impacto que elas vêm causando. Mas, para que elas continuem sendo relevantes socialmente, é preciso fazer com que a população em geral compreenda e experimente esse conhecimento produzido pelas universidades, fazendo-o não ficar concentrado somente na comunidade acadêmica. Assim sendo, cabe a reflexão sobre os possíveis movimentos que a universidade pode realizar para que esse compromisso em difundir o conhecimento não seja negligenciado. Para tanto, Luiz Síveres (2013) ressalta:

A universidade, como uma entidade do complexo sistema social, pela própria razão de ser, precisa assumir uma maneira de dialogar e, num primeiro movimento, é toda a organização que se coloca numa atitude dialogante, e tal esforço não se realiza de forma unidirecional, mas de maneira pluridirecional, compreendendo a instituição como uma energia propositiva na realidade multidimensional da sociedade. Nessa dinâmica, o diálogo dos sujeitos acadêmicos, com a diversidade de informações, de conhecimentos e de saberes, potencializa o projeto pedagógico institucional. (SÍVERES, 2013, p. 24).

Alguns autores, como o próprio Síveres (2013), procuram enfatizar essas reflexões apontadas e, com isso, propor um diálogo entre acadêmicos sobre a função social das práticas extensionistas, dando abertura a (re)pensarmos como a instituição pode ser significativa no processo de formação docente inicial e continuada. Assim, é essencial que o docente em formação possua contato (também) com uma realidade não acadêmica, tendo experiências em atividades educacionais não escolares e construindo suas ferramentas para lidar com o outro sujeito do processo educativo e suas demandas.

Dessa forma, entende-se que a função social das ações de extensão estão para além de uma demanda mercadológica ou até mesmo assistencialista. Deduz-se, ainda, que há um compromisso ético em torno das práticas docentes que tem, por finalidade, um preparo para a vida em sociedade, fazendo com que este sujeito possa existir no mundo de modo efetivo e significativo com seus saberes. Da mesma maneira, numa contemporaneidade que cada vez mais cobra dos educadores ações que sejam relevantes às demandas de seu entorno e, ao mesmo tempo, vinculadas aos saberes globais, o docente em formação necessita de uma formação plural, pautada em múltiplos espaços, vivências e culturas. 
A Extensão Universitária como possibilidade de formação docente para além da sala de aula

Essa reflexão está no centro da Educação/Pedagogia Social e é importante para compreendermos qual é o seu possível alcance e o objetivo. Para isso, se faz necessário, utilizando uma expressão popular, "trocar uma ideia" com o entorno da universidade, que em nosso estudo de caso, pode ser definida como uma troca de ideias entre as experiências de uma universidade em uma região periférica do Rio de Janeiro e a chegada dos educandos desse contexto à academia.

\section{A periferia chega à universidade: uma experiência extensionista e periférica em São Gonçalo.}

Nosso estudo de caso está situado em São Gonçalo, segundo município mais populoso do Rio de Janeiro - com mais de um milhão de habitantes - e localizado na Região Metropolitana. Os problemas do município não são poucos, indo desde a falta de saneamento em diversas áreas à problemas no sistema educacional básico. Como podemos ver na avaliação do Índice de Desenvolvimento da Educação Básica (IDEB) de 2019, São Gonçalo obteve o quarto pior desempenho nos anos iniciais do ensino fundamental do estado (nota 4,6) e o oitavo pior na avaliação dos anos finais do ensino fundamental (nota 3,7).

O nosso espaço de pesquisa, a Faculdade de Formação de Professores da UERJ, localiza-se no Patronato, bairro que possui no seu entorno as favelas denominadas "Morro do Feijão" e "Morro da Jaqueira". A FFP é o segundo maior campus da Universidade do Estado do Rio de Janeiro (atrás apenas da sede, no Maracanã), tendo papel importantíssimo para São Gonçalo por se tratar da primeira instituição de ensino superior pública e gratuita na cidade, dedicada exclusivamente, desde a sua fundação, em 1973, à formação de professores e a produção de conhecimentos direcionados a educação em vários campos científicos.

Segundo dados do Atlas do Desenvolvimento Humano no Brasil de $2013^{2}$, que é realizado de acordo com os censos de 1991, 2000 e 2010, São Gonçalo se encontra na $795^{\circ}$ posição. O índice pondera aspectos como renda, longevidade e educação. Devido a fatores diversos, a região se encontra em uma situação delicada e com perspectivas de mudança complexas com relação a esse panorama, uma vez que o poder público toma poucas iniciativas para progredir neste quadro.

\footnotetext{
${ }^{2}$ Com base em dados do IBGE (Instituto Brasileiro de Geografia e Estatística).
} 
Mediante a essas circunstâncias, é necessário pontuar que, ainda que o docenteextensionista busque basear-se nesses (e em outros) dados, os horizontes apresentados não devem servir como um empecilho para articular ações na região, mas sim, como uma forma de produzir práticas mais efetivas, dado o melhor reconhecimento das demandas do município. Dessa maneira, considerando tais demandas, as ações extensionistas acabam ganhando ainda mais destaque na localidade, visto que essas podem ajudar na condução de diálogos acerca de pautas como raça, sexualidade, cultura, criminalidade, cidadania e outras que podem ser diversificadas até mesmo em uma determinada região do município.

No estudo de caso trabalhado, esse diálogo efetivo ocorre, também, por meio dos estudantes universitários de origem popular (EUOP's) que atuam nas práticas extensionistas. O conceito de "estudante universitário de origem popular" é definido a partir da construção do perfil de aluno considerando três aspectos centrais: renda média familiar de até 3 salários-mínimos; residir em região periférica, subúrbio ou favela; e, como terceiro critério, ter pais que possuem escolaridade até o ensino fundamental (cf. GABRIEL; MOEHLECK, 2011).

Em relação a esses EUOP's, faz se necessário ponderar brevemente sobre as políticas afirmativas que levaram ao ingresso de jovens de periferias às universidades. Tais políticas possuem como objetivo central:

[...] eliminar desigualdades historicamente acumuladas, garantindo a igualdade de oportunidades e tratamento, bem como compensar perdas provocadas pela discriminação e marginalização, decorrente de motivos raciais, étnicos, religiosos, de gênero e outros. (SANTOS, 1999, p. 25).

É importante ressaltar ainda que, "no Brasil, as políticas de ação afirmativa assumem hoje grande destaque e merecem uma referência especial" (SANTOS, 2004, p. 70). Embora essas exigências tenham se revelado efetivas já a partir do ano de 2001, foi somente em 2012 que as políticas de ações afirmativas se efetivaram em nível federal. No âmbito estadual, essas medidas vêm sendo adotadas desde 2000, sendo a Universidade do Estado do Rio de Janeiro pioneira ao adotar o sistema de reservas de vagas, com base na Lei Estadual 3524/2000.

No entanto, ainda que com o ingresso de alunos das classes populares nas universidades, a luta pela ocupação do espaço acadêmico por "outros saberes" segue árdua. Pois, para tal engenharia, é necessário o ímpeto em combater certo senso comum - que já possui longa história - que termina por colaborar no processo de hierarquização 
A Extensão Universitária como possibilidade de formação docente para além da sala de aula

dos conhecimentos, o que acaba contribuindo para o afastamento dos grupos socialmente mais vulneráveis. Assim, os muros invisíveis, leia-se, as limitações socioeconômicas, políticas, metodológicas e outras mais, na maioria das vezes, são mais excludentes que as próprias barreiras físicas.

Por fim deste tópico, cabe destacar ainda que o impacto das mudanças nas periferias e favelas afetam diretamente a estrutura da universidade. Dessa maneira, perceber essas rupturas e mudanças na situação atual nos convida a tentar compreender como se percebem esses sujeitos que estão inserindo essas transformações. Para exemplificar tais experiências, tem-se como estudo de caso algumas das considerações preliminares encontradas nas práticas extensionistas dos grupos que compõem o TEAR (Troca de Experiências em Ações Extensionistas), um projeto de extensão situado na Faculdade de Formação de Professores da UERJ. Da mesma forma, corroboramos com a importância da utilização de metodologias e teorias que busquem um olhar mais atento sobre os outros, reconhecendo como positivas suas experiências, demandas e, sobretudo, diferenças; é o que veremos através das Pedagogias da Convivência - de Xesús Jares (2008) - e da Hospitalidade - de Isabel Baptista (2005).

\section{A educação em espaços não escolares em uma experiência de troca de saberes: o caso do TEAR na Faculdade de Formação de Professores (FFP/UERJ)}

As discussões quanto à extensão e à educação em espaços não escolares ainda são, regularmente, passadas de modo superficial na formação docente. A possibilidade de atuação em um espaço não escolar, quando abordada, é feita de maneira simples e isso faz com que o educador, uma vez que enfrente essa realidade, se depare com algo ao qual, de fato, ele não foi formado para atuar. Nesse caso, a ausência de recursos teóricos pode ser fatídica para a má execução da prática. Todavia, entende-se que a formação acadêmica pode vir a auxiliar com o campo teórico algo que já vem sendo produzido em sua prática ou até mesmo que irá ser produzido. Em suma, a teoria não é mais importante que a prática ou vice-versa, ambas têm a sua relevância em cada contexto.

A Faculdade de Formação de Professores da UERJ, por exemplo, passou a inserir em sua grade uma disciplina universal eletiva intitulada "Educação em Espaços Não Escolares", que possui como uma das suas finalidades trazer a pauta intitulada para a formação docente. Com isso, acredita-se que os alunos ampliem o horizonte de atuação da docência e também sejam iniciados na capacitação para a atuação nesses ambientes. Ao longo do curso, são articulados alguns dos principais estudos de autores que dialogam 
sobre a temática, como, por exemplo, Jaume Trilla (ARANTES; GHANEM, TRILLA, 2008), Xesús Jares (2008), Isabel Baptista (2005) e Paulo Freire (1997).

Tendo isso, é imprescindível que a universidade busque fazer uma autorreflexão quanto ao modo como são concebidas essas práticas, quem são os sujeitos envolvidos no processo, quais são as principais demandas requeridas pelo determinado grupo analisado e quais são as pautas que estão inseridas nos mesmos. Devido à ausência de disciplinas obrigatórias que tratem sobre as práticas da docência fora do ambiente escolar nessa instituição, o estudo sobre como estão sendo realizadas essas ações torna-se valioso à medida que é possível notar por quais caminhos estamos conduzindo tais procedimentos.

Para tanto, o TEAR busca observar metodologicamente as ações de alguns grupos do Departamento de Extensão da Faculdade de Formação de Professores da UERJ. De modo a promover o encontro de práticas outrora separadas, uma das metodologias do TEAR é a construção de diários de campo sob a luz da fenomenologia de Edmund Husserl. ${ }^{3}$ Além disso, o grupo teoriza sobre alguns autores do campo da Pedagogia Social, da História, da Sociologia, da Filosofia e de outras áreas do conhecimento que possam vir a somar de modo à discussão nos apontando possíveis caminhos para uma prática realizada de modo efetivo aos objetivos vislumbrados.

Com isso, espera-se estimular a troca de saberes, além de identificar o panorama das ações produzidas pelos grupos e planejar novas metas. Ao nos debruçarmos sobre a fenomenologia de Husserl (1975), podemos perceber ganhos importantes para os nossos estudos no campo. Inspirados no filósofo alemão, que almejava transgredir a lógica positivista (dominante em sua época), o TEAR utiliza-se de um método de escrita de diários de campo que, basicamente, pode ser notado como um método de pesquisa baseado na experiência de conhecer o outro através de três perspectivas: noema, noese e variação eidética (cf. DEPRAZ, 2011; FERREIRA, 2015). O intuito da divisão é de que seja possível analisar o fenômeno a partir de três perspectivas e, assim, chegar o mais próximo possível de um conhecimento abrangente, ou seja, um conhecimento não pautado exclusivamente na perspectiva do autor.

\footnotetext{
3 Segundo Ferreira (2015), os diários de campo são divididos baseados na estrutura do método fenomenológico de Husserl. Dessa forma, noema, noese e variação eidética constituem o diário de campo. O noema refere-se à parte mais objetiva do relato analisado; é a descrição do fenômeno a partir de uma percepção mais imparcial possível. O noese, ao contrário, seria a parte subjetiva; é aqui que o sujeito pode escrever suas lembranças, sentimentos e percepções do fenômeno, ou seja, como esse sujeito, o analisador, reagiu ao objeto. A variação eidética ou redução eidética é a forma de relatar o fenômeno a partir da visão e dos sentimentos dos outros que fazem parte da ação. O relato é feito a partir do que o outro demonstra mediante ao fenômeno (FERREIRA, 2015, p. 8).
} 
A Extensão Universitária como possibilidade de formação docente para além da sala de aula

Assim, ainda que não seja possível produzir uma análise das relações humanas ausente de subjetividade, isso não pode vir a se tornar um pretexto para que essa não seja almejada. Compreendemos que, a partir dos estudos do TEAR, a inspiração fenomenológica se mostra como um caminho potente para realizar tais investigações a fim de atingir um olhar amplo sobre a relação com o outro, trazendo não só outras perspectivas, mas também a maior riqueza de detalhes possível, permitindo assim que o próprio leitor dialogue com a fonte e tire suas próprias conclusões sobre o fenômeno. Dessa forma, espera-se atingir um olhar sobre o educando tendo o próprio como protagonista e, ao mesmo tempo, levando em conta a experiência dos outros agentes que estão participando do fenômeno - em nosso caso, a extensão.

Para atingir tais reflexões, os apontamentos de Xesús Jares (2008) se fazem oportunos. $\mathrm{O}$ autor irá tratar da convivência humana e sua complexidade sugerindo que as relações humanas são permeadas por conflitos inerentes ao nosso desejo. Assim sendo, o que gera tais conflitos, como proposto por Jares (2008), são as diferenças existentes em nossas próprias maneiras de existir no mundo. Quando transportamos essas noções para a prática, em especial, para o contexto que analisamos, podemos notar alguns aspectos relevantes. Ao realizar uma ação de extensão em uma universidade pública de uma região periférica do Rio de Janeiro, há de se considerar que as barreiras de classe e status sociais são realçadas. $\mathrm{O}$ ensino superior no Brasil foi marcado por um baixo acesso de discentes e docentes oriundos de regiões periféricas e, desse modo, é possível inferir que o afastamento de tal realidade pode ser um ponto de conflito desses grupos no momento da atividade de extensão. Jares (2008), no entanto, aponta que tais práticas (sócio)educativas, ainda que possuam em suas relações sociais um inerente conflito, não precisam vivenciar esse de modo violento. O conflito, dessa forma, pode servir para a construção de novos saberes, a partir, justamente, das diferenças entre os sujeitos.

Por outro lado, esses conflitos, se tratados de modo violento, podem ser notados, por exemplo, quando um docente exerce sua autoridade de um modo negativo, isto é, ignorando todo o contexto, desejo e saberes dos alunos, transmitindo assim um conteúdo de modo inflexível e distante. Esse afastamento ocasiona um processo formativo no qual o docente não vai ao encontro do outro, não busca conhecer a realidade dos educandos. Pensando na formação docente, Isabel Baptista irá trazer colocações que podem sugerir maneiras de como se preparar para lidar com o outro. Segundo as palavras da autora:

A forma que equacionamos a relação com os outros depende muito da concepção de "outro" que tivermos em referência. O outro é uma ameaça, um inimigo em potencial, alguém que simplesmente toleramos, ou pelo contrário, é alguém que só por 
efeito da sua entrada na esfera da nossa mesmidade, representa uma mais-valia, uma ocasião de enriquecimento pessoal? (BAPTISTA, 2005, p. 45)

Baptista (2005) irá propor o que convenhamos chamar de "Pedagogia da Hospitalidade". A hospitalidade tem como premissa o acolhimento, mas, para tanto, se faz substancial meditar qual postura ética o educador deve ter para com o educando. Uma vez que somos seres ímpares que compõem uma sociedade heterogênea, quais movimentos precisarão ser realizados para ir de encontro a este aluno que, em contrapartida, faz o mesmo movimento de ir ao encontro do docente? Dessarte, Baptista sugere que somos atravessados em todas as relações sociais; nesse caso, o outro sempre irá deixar uma marca em nós - e nós nele. Nessa reflexão, ao ensaiar sobre a filosofia da alteridade de Emmanuel Levinas (1980), Luíz Síveres e Paulo Giovanni Rodrigues de Melo (2012) apresentam com eficiência essa concepção pedagógica que estamos trabalhando aqui.

Falar de uma pedagogia da hospitalidade significa abrir a morada, favorecendo ao Outro um lugar de cortesia, de responsabilidade e bondade. Esse espaço não se faz apenas com palavras afáveis, mas através de gestos concretos que convidam o Outro a uma vivência do acolhimento, do descanso, refúgio, alimento, ajuda ou conforto. Por isso, para uma experiência de hospitalidade, é preciso abertura, característica fundamental para uma verdadeira pedagogia da hospitalidade, permitindo que o Outro crie vínculos e opte por ficar numa relação ética. Esse vínculo é favorecido quando se autoriza a entrada do Outro no espaço próprio sem reservas ou desconfianças, ajudando-o a se sentir seguro, algo que somente ocorre quando se sente acolhido na casa, na vida e na história. (SÍVERES; MELO, 2012, p. 35).

De modo intrínseco, pensar na condição do outro está diretamente ligado a pensar na condição do "eu" enquanto um sujeito que necessita ser formado para a atuação com o "outro". Nesse ponto, Baptista nos auxilia de modo significante em sua reflexão. Para tanto, a autora aponta que "a descoberta do outro, condição necessária para a descoberta de si mesmo, deve ser marcada pela consciência da interdependência e pelo sentido de proximidade que suportam a verdadeira cultura de paz." (BAPTISTA, 2005, p. 47). Ter essa consciência de si, é um item deveras importante, pois é dessa experiência de autoconhecimento que notamos como somos atravessados por esses sujeitos e suas requisições.

Dessa forma, vê-se que as proposições de Jares (2008) e Baptista (2005) auxiliam de modo significante nossa análise, sendo concebíveis novas possibilidades educativas a 
A Extensão Universitária como possibilidade de formação docente para além da sala de aula

partir das práticas delas. As noções de hospitalidade, conflito e convivência dialogam para outras realidades, tornando-se fulcrais para analisar contextos diversos, sem ignorar, contudo, a experiência de educadores sociais que atuam em dessemelhantes cenários e possuem um conhecimento aprofundado da prática das suas ações. Esse conhecimento teórico deve ser usado como um complemento de uma perspectiva, e não como uma regra necessariamente.

Dessarte, uma vez que é difícil aferir com certeza ao longo da formação docente quais conteúdos serão trabalhados no ambiente não formal, torna-se necessário que o docente esteja aberto a acolher, ouvir e dialogar com o educando-extensionista. Dessa forma, esse estudo não procura apontar que existe uma "fórmula" para qual as ações se tornam válidas ou não, mas sim, pensar, analisar e traçar reflexões sobre como essas estão sendo produzidas e seus possíveis impactos, que continuarão sendo estudados e meditados.

A partir da experiência obtida neste primeiro momento da pesquisa proposta pelo TEAR, foi possível notar pautas plurais como raça, pobreza, formação docente, educação infantil, cultura, dentre outras inseridas nos grupos e coletivos do Departamento de Educação da Faculdade de Formação de Professores (FFP/UERJ). A atuação dos estudantes de origem popular nas práticas é elementar para que a universidade consiga mediar o contato com aqueles que estão ao seu entorno, além disso, é estimável que ao serem atravessados por essa experiência na formação docente, esses estudantes e outros ajudem a romper as barreiras para difusão do saber.

Essas barreiras podem ser alicerçadas por aspectos que tangem localidades periféricas como a criminalidade, o preconceito e outras formas de violência. Nesse caso, a insensibilidade em mediar o conhecimento pode ser um elemento fatídico nesse processo e acaba por promover o distanciamento desses sujeitos para com a universidade. Do contrário, os movimentos trabalhados pelo TEAR estimam integrar cada vez mais essas esferas sociais de modo a utilizar as Pedagogias da Convivência e da Hospitalidade como modelos para pensarmos as relações de alteridade entre os sujeitos e assim tornálos protagonistas do processo formativo. Considera-se, dessa forma, pois se acredita que não há sentido prático na universidade sem a participação ativa da comunidade ao seu redor. 


\section{Considerações Finais}

Ao analisarmos a trajetória da extensão universitária, podemos observar que, paulatinamente, esta vem ganhando um espaço de prática educativa que pode vir a realizar a transformação social para com as camadas empobrecidas. Por ser etapa fundamental da formação docente, é possível afirmar que esta é uma ferramenta de transformação também na jornada desse educador em formação, sobretudo, como no estudo de caso trabalhado, considerando-se aqueles estudantes de origem popular. Assim, vislumbra-se que a extensão pode vir a ser um recurso importante no diálogo entre a universidade e a população em seu entorno, de modo que as trocas entre essas duas instâncias venham dar sentido à vigência da universidade.

Em contextos de periferia, a prática extensionista tende a ser uma prática fundamental, pois, por vezes, ela atua no local da ausência. Geralmente, as ações extensionistas (que também podem ser consideradas práticas de educação social) buscam trabalhar com aqueles que por vezes são marginalizados na sociedade e a universidade tem como uma de suas funções sociais ir de encontro a esses grupos. Mas esse fator não pode isentar a responsabilidade daqueles que possuem como encargo garantir os direitos básicos da população.

Pensar na formação docente atrelada a essas práticas é um item chave para a reflexão proposta neste trabalho. Quando consideramos as demandas contemporâneas atribuídas à formação docente, rejeitamos uma perspectiva educacional centrada em "critérios de submissão do nacional ao internacional", considerando como ideal a assunção da noção de que "o local e o global estão inextricavelmente ligados em uma rede comunicacional" (PORFÍRIO, 2012, p. 129) e devem ser considerados nas práticas educacionais. Ainda assim, vale destacar que, por mais atualizado e preparado que seja um curso universitário, o professor não sairá "pronto" para tais demandas após formado, sendo necessário, ainda, novas atualizações, práticas e aperfeiçoamentos futuros - e permanentes (cf. ZAINKO, 2010, p. 121-122). Dessa maneira, inferimos as práticas extensionistas como aliadas nessa "busca formativa", em particular, ao percebermos o quanto essas auxiliam para uma formação mais voltada às ações que busquem atuar nas demandas específicas da realidade (espacial ou temporal) na qual estão inseridas.

Consequentemente, vê-se como referenciais teóricos relevantes para pensar essas ações, a Pedagogia da Hospitalidade de Isabel Baptista e a Pedagogia da Convivência de Xesús Jares, pois se nota que esses modelos, provenientes do campo da Pedagogia Social, auxiliam e trazem contribuições significativas para (re)pensarmos as práticas educativas 
A Extensão Universitária como possibilidade de formação docente para além da sala de aula

com os grupos socialmente mais vulneráveis e a importância do pensar a educação não escolar na formação docente.

Ao trabalharmos o TEAR (Troca de Experiências em Ações Extensionistas) de modo a pensar na atuação dos grupos de extensão da Faculdade de Formação de Professores da UERJ, em São Gonçalo, podemos observar que as trocas de experiências entre educadores, educandos e os demais sujeitos que compõem uma prática educativa são fulcrais para o aprimoramento das práticas. Para tanto, devem ser trabalhadas a dimensão da escuta e da fala, isto é, do diálogo. O diálogo pode ser uma importante ferramenta para construirmos uma relação efetiva entre a universidade, seus sujeitos e seu entorno.

Faz-se necessário, portanto, buscar o estreitamento teórico e prático entre os profissionais da Educação Superior, da Educação Básica e da Educação Social, de modo a que essas ações legais sejam cumpridas e, para mais, constituam um compromisso ético dos educadores para com aqueles que não têm acesso à diversidade de práticas educativas e culturais existentes nos diversos espaços sociais e não somente nas escolas e universidades.

Por isso, cremos que as práticas de extensão podem ajudar a romper estruturas acadêmicas conservadoras e burocráticas, dando ao "outro" a oportunidade de interagir com a universidade. Reconhecendo a sua importância para a sociedade como um todo, as mesmas poderão permanecer atemporais, pois elas se comunicam com os indivíduos que habitam a localidade.

O estudo sobre as ações extensionistas, a formação docente e o impacto sobre os grupos sociais se fazem relevantes para entender como a educação não formal potencializa laços de convivência entre seres humanos tão distintos. Essa troca será possível a partir de posturas éticas de proximidade, que irão gerar formas de conhecimento distintas das pretendidas pelas instituições formais, mas de grande relevância para a formação da identidade social dos sujeitos contemporâneos.

As investigações propostas pelo TEAR tendem a reafirmar a importância de se estabelecer diálogos e trocas de experiências entre os sujeitos para pensarmos metodologias que possam ser aplicadas em diferentes contextos onde a prática extensionista venha a atuar. Esse movimento é fulcral para que possamos trabalhar a formação docente inicial e continuada e alcancemos os sujeitos de acordo com aquilo que a eles é necessário para a sua formação humana. 


\section{Referências}

ARANTES, Valéria Amorim, GHANEM, Elie; TRILLA, Jaume. Educação formal e não formal: Pontos e Contrapontos. São Paulo: Ática, 2008.

BAPTISTA, Isabel. Dar rosto ao futuro: a educação como compromisso ético. Porto: Profedições, 2005.

BRASIL. Lei n. 9.394/96, de 20 de dezembro de 1996. Lei de Diretrizes e Bases da Educação Nacional. Brasília, 1996.

CHARLOT, Bernard. O professor na sociedade contemporânea: um trabalhador da contradição. Revista da FAEEBA - Educação e Contemporaneidade, Salvador, v. 17, n. 30, p. 17-31, jul./dez., 2008.

CONSELHO NACIONAL DE EDUCAÇÃO (CNE). Resolução CNE/CP no 02/2015, de $1^{\circ}$ de julho de 2015. Define as Diretrizes Curriculares Nacionais para a formação inicial em nível superior e para a formação continuada. Brasília, 2015.

CROSS, Di; THOMSON, Simon; SIBCLAIR, Alexandra. Research in Brazil: A report for CAPES by Clarivate Analytics. Disponível em: http://portal.andes.org.br/imprensa/noticias/imp-ult-992337666.pdf. Acesso em 20 de fevereiro de 2021.

DEPRAZ, Natalie. Compreender Husserl. Petrópolis: Vozes, 2011.

DUBEUX, Ana. Extensão universitária no Brasil: democratizando o saber da universidade na perspectiva do desenvolvimento territorial. Sinergias - Diálogos educativos para a transformação social, Porto, v. 6, p. 9-24, jan./jun., 2018.

FERREIRA, Arthur Vianna. O uso da fenomenologia nas práticas de estágio supervisionado para licenciaturas. Rev. Brasileira de Ensino Superior, Passo Fundo, v. 1, n. 2, p. 5-14, out./dez., 2015.

Transpor muros para abrir universidades: as práticas extensionistas e a visibilidade da pobreza em pesquisas na formação docente no ensino superior. In: FERREIRA, Arthur Vianna; LOPES, Lucas Salgueiro; DIAS, Thiago Simão. Fora da Sala de Aula: Formação docente e estudos sobre pobreza e educação. Rio de Janeiro: Autografia, 2019.

FORUM NACIONAL DE PRO-REITORES DE EXTENSÃO DAS UNIVERSIDADES PUBLICAS BRASILEIRAS (1-3:1987-1989). Documentos Finais, Florianópolis: Ed. da UFSC, 1990.

FREIRE, Paulo. Pedagogia da autonomia. São Paulo: Paz e Terra, 1997. 
A Extensão Universitária como possibilidade de formação docente para além da sala de aula

GABRIEL, Carmen Teresa. Conhecimento escolar, cultura e poder: desafios para o campo do Currículo em "tempos pós". In: Antônio Flávio Moreira; Vera Maria Candau. Multiculturalismo: diferenças culturais e práticas pedagógicas. Petrópolis: Vozes, 2008.

GABRIEL, Carmen Teresa; MOEHLECK, Sabrina. Estratégias para a permanência de EUOPS na UFRJ: a experiência do Projeto Conexões de Saberes. Revista Extensão na UFRJ. Rio de Janeiro: Núcleo de Produção Editorial UFRJ, n. 0, p. 40-44, jun., 2011.

HUSSERL, Edmund. Investigações Lógicas. São Paulo: Abril Cultural, 1975.

JARES, Xesús. Pedagogia da Convivência. São Paulo: Palas Athena, 2008.

LEVINAS, Emmanuel. Totalidade e infinito: ensaio sobre a exterioridade. Lisboa: Edições 70, 1980.

NÓVOA, António. Os Professores na Virada do Milênio: do excesso dos discursos à pobreza das práticas. Educação e Pesquisa, São Paulo, v. 25, n. 1, p. 11-20, jan./jun., 1999.

PORFÍRIO, Luciana Cristina. O local e o global e as perspectivas teóricas da comparação para os estudos em torno da formação do professor. Educação e Fronteiras On-Line, Dourados, v. 2, n. 5, p. 114 -131, maio/ago., 2012.

SANTOS, Boaventura de Sousa. A universidade no século XXI: para uma reforma democrática e emancipatória da universidade. São Paulo: Cortez, 2004.

SANTOS, Hélio [et al]. Políticas públicas para a população negra no Brasil. Relatório da ONU, 1999.

SANTOS, Marcos Pereira dos. Contributos da extensão universitária brasileira à formação acadêmica docente e decente. Revista Conexão UEPG, Ponta Grossa, v. 6, n. 1, p. 10-15, jul./dez., 2010.

SÍVERES, Luíz. A Extensão Universitária como um Princípio de Aprendizagem. Porto Alegre: Liber Livro, 2013.

SÍVERES, Luíz; MELO, Paulo Giovanni Rodrigues de. A pedagogia da hospitalidade a partir da filosofia da alteridade em Levinas. Conjectura: Filosofia e Educação, Caxias do Sul, v. 17, n. 3, p. 34-48, set./dez., 2012.

SOUSA, Ana Luísa. Lima. A história da extensão universitária. Campinas: Editora Alínea, 2010.

CORREIA, Ovídio Valois. A extensão universitária no Brasil: Um resgate histórico. Sergipe: Editora UFS, 2000. 
ZAINKO, Maria Amélia S. Políticas de formação de professores na universidade pública: uma análise de necessidades, entre o local e o global. Educar, Curitiba, n. 37, p. 113-127, maio/ago, 2010.

* Alan Navarro Fernandes é licenciando em História pela Faculdade de Formação de Professores da UERJ (FFP/UERJ). Bolsista do Programa de Iniciação à Docência (PIBID). Membro do Grupo Fora da Sala de Aula. Dedica-se também à produção de materiais didáticos na rede privada de ensino. É idealizador e professor voluntário da disciplina de História no Atitude Pré-Vestibular Social.

E-mail: alan.navarro08@gmail.com

ORCID: https://orcid.org/0000-0002-6370-9821

** Lucas Salgueiro Lopes é Mestrando em Educação - Processos Formativos e Desigualdades Sociais na Faculdade de Formação de Professores da UERJ (FFP/UERJ). Bolsista CAPES. Pós-graduando em Educação Básica - Gestão Escolar pela FFP/UERJ. Possui Licenciatura Plena em História pela FFP/UERJ e em Sociologia pelo Centro Universitário Internacional. Membro do Grupo Fora da Sala de Aula.

E-mail: salgueirollucas@gmail.com

ORCID: https://orcid.org/0000-0003-4111-2685

*** Arthur Vianna Ferreira é Doutor em Educação: Psicologia da Educação pela PUC-SP. Professor adjunto do Departamento de Educação da FFP-UERJ e docente do PPGEdu (Programa de Pós-Graduação em Educação: Processos Formativos e Desigualdades Sociais) da Faculdade de Formação de Professores da UERJ (FFP/UERJ). Coordenador-pesquisador do Grupo Fora da Sala de Aula.

E-mail: arthuruerjffp@gmail.com

ORCID: https://orcid.org/0000-0002-5297-1883 